\title{
Association between presence of 20 or more natural teeth and all-cause, cancer-related, and cardiovascular disease-related mortality: Yamagata (Takahata) prospective observational study
}

Shigeo Ishikawa ${ }^{*} \mathbb{0}$, Tsuneo Konta ${ }^{2}$, Shinji Susa ${ }^{3}$, Kenichi Ishizawa ${ }^{3,5}$, Hitoshi Togashi $^{4}$, Yoshiyuki Ueno ${ }^{5}$, Hidetoshi Yamashita ${ }^{5}$, Takamasa Kayama ${ }^{5}$ and Mitsuyoshi lino ${ }^{1}$

\begin{abstract}
Background: Several studies have surveyed the relationship between the presence of $\geq 20$ natural teeth and mortality. However, very few have evaluated this association over a long-term follow-up of more than ten years within a large population in Japan. This study aimed to prospectively confirm the associations between mortality and the presence of $\geq 20$ natural teeth within a community-based population in Japan.

Methods: A prospective observational study including 2208 participants aged $\geq 40$ years was conducted in Takahata Town, Japan, between May 2005 and December 2016. All participants answered a self-administered questionnaire to provide their background characteristics, including their number of teeth. The participants were classified into two categories based on their self-reported number of teeth ( $<20$ and $\geq 20$ teeth). Hazard ratios (HR) and $95 \%$ confidence intervals (Cl) were calculated using Cox proportional-hazards regression model to assess risk factors for all-cause, cancer-, and cardiovascular disease-related mortality.

Results: The total follow-up period was 131.4 \pm 24.1 months (mean \pm SD). After adjusting for covariates, the risk of all-cause mortality was significantly higher in the group with $<20$ teeth than in those with $\geq 20$ teeth $(H R=1.604,95 \%$ $\mathrm{Cl} 1.007-2.555, p=0.047)$. However, the risk of cancer- and cardiovascular disease-related mortalities was not statistically significant between the two groups.
\end{abstract}

Conclusion: In this study, participants with $<20$ teeth had a significantly higher risk of all-cause mortality, although the difference was borderline significant. These results emphasize the importance of having $\geq 20$ natural teeth for a healthy life expectancy.

Keywords: Tooth loss, Mortality, Prospective study, Observational study, Proportional-hazards model

*Correspondence: shigeo_ishikawa2011@yahoo.co.jp

${ }^{1}$ Department of Dentistry, Oral and Maxillofacial Plastic

and Reconstructive Surgery, Faculty of Medicine, Yamagata University,

2-2-2 lida-nishi, Yamagata 990-9585, Japan

Full list of author information is available at the end of the article

\section{Background}

In Japan, a political campaign for the preservation of $\geq 20$ natural teeth at the age of 80 years has been conducted for more than 30 years by the Ministry of Health, Labour and Welfare $[1,2]$. The outreach for the importance of keeping $\geq 20$ natural teeth at the age of 80 years 
was successful, and the proportion of such individuals has been increasing in Japan [3]. Moreover, there has been growing evidence justifying the importance of having $\geq 20$ natural teeth, as opposed to simply having several teeth regardless of the total number of teeth. Maintaining $\geq 20$ teeth is crucial not just for mastication [4-6], but also beneficial for other aspects such as, decreasing the risk of onset of dementia [7], incident falls [8], and the requirement for nursing care [9].

The association between mortality and number of teeth has also attracted interest. Events such as tooth loss can lead to hypoactivity of the masticatory system, and, in turn, unhealthy diet patterns, which can negatively influence general health. Consequently, tooth loss has the potential to affect mortality [10-12]. The systemic inflammatory response in periodontal disease, a major cause for tooth loss, is a well-known risk factor for cardiovascular and malignant diseases [10-12]. Bacterial colonization and the generation of carcinogens such as nitrosamine due to periodontal disease are also frequently reported as potential risk factors for mortality, specifically cancer-related [10-12]. Based on the above hypotheses (Fig. 1), many prospective cohort studies worldwide have attempted to survey this relationship. Among these, several have surveyed the relationship between the presence of $\geq 20$ natural teeth and mortality [13-16]. To the best of our knowledge, seven prospective studies on this topic have been published in Japan [17-23]. However, the participants of five of these studies were elderly people aged over 65 years [18-20, 22, 23], and only two studies were performed among community-dwelling people within the broad age range of Japanese adults [17, 21]. Furthermore, among these two studies, one had a relatively short follow-up period of less than 6 years [17].

Therefore, a prospective observational study was conducted with 2000 participants chosen from among community-dwelling people within the broad age range of Japanese adults, using data from a community-based cohort study, the Takahata study. The study was conducted over a period of more than ten years and was aimed at confirming the association between the presence of $\geq 20$ natural teeth and mortality.

\section{Methods}

\section{Study design and participants}

This study was performed as part of the ongoing Molecular Epidemiological Study utilizing the Regional Characteristics of twenty first Century Centers of Excellence (COE) Program in Japan. This study was approved by the ethics committee of Yamagata University School of Medicine (No-2019-403).

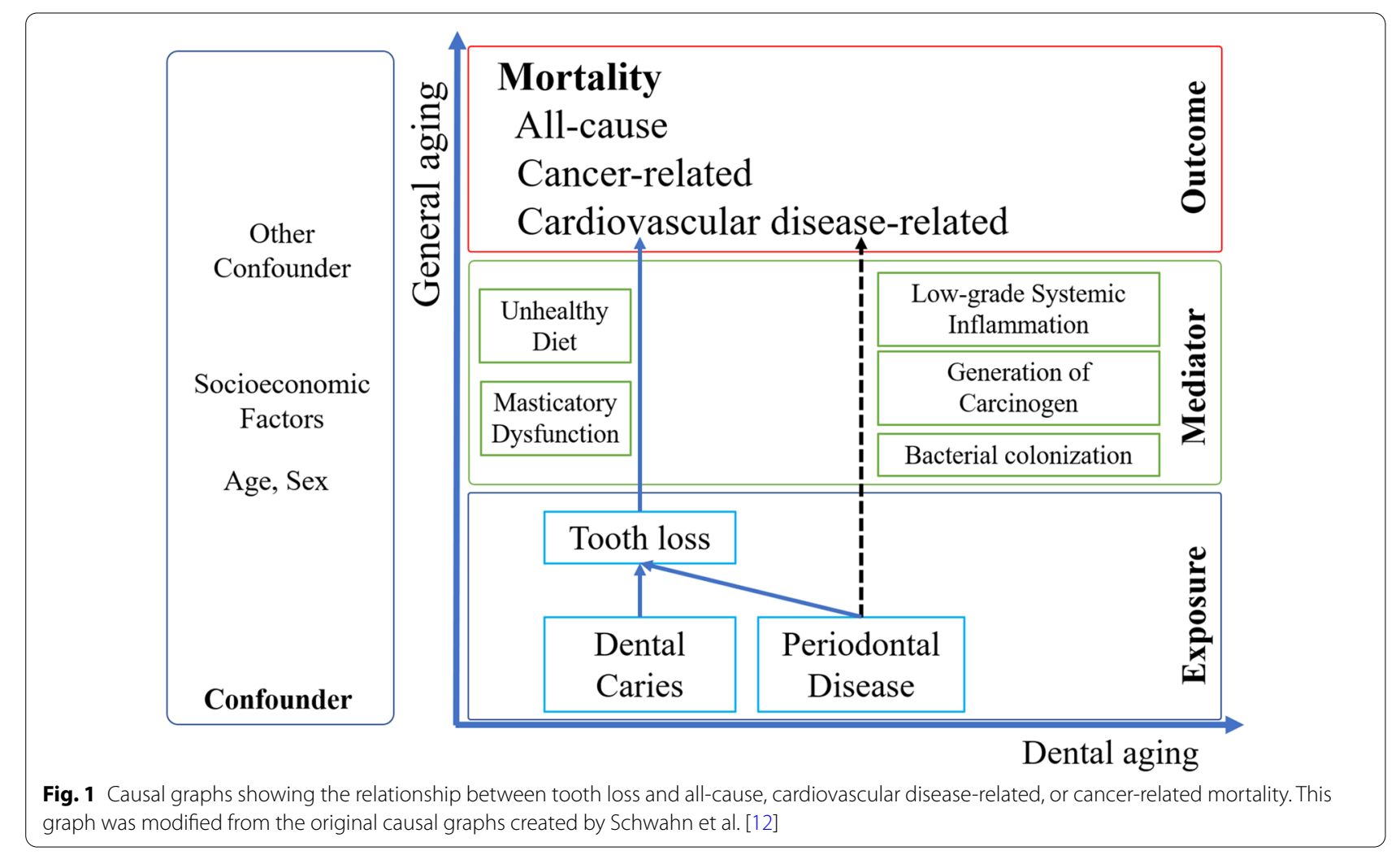


The study participants were part of a communitybased annual health check, in which residents of Takahata Town in Yamagata Prefecture, Japan, aged $\geq 40$ years were invited to participate. The participants were in good general health; those who had subjective symptoms did not participate. Between May 2005 and December 2016, 2942 participants (1301 men, 1641 women) were enrolled. Fifty-nine participants were lost to follow-up after moving to other areas. Participants were followedup for approximately 140 months and assessed for associations between their number of teeth and all-cause, cancer-related, and cardiovascular disease-related mortalities. Of the total number of participants, 734 were excluded due to incomplete data regarding their number of teeth. In total, 2208 participants were entered into the final statistical analysis.

\section{Measurements}

At baseline, a postal survey in the form of a self-administered questionnaire was distributed among the participants to assess lifestyle factors, medical history, and oral health-related aspects, such as their number of teeth and dietary aspects, including alcohol consumption. This questionnaire has been used in previous studies [24, 25]. The number of teeth was assessed via a single-item question that was as follows: "How many teeth do you have now? (Fixed prostheses were counted; removable prostheses were not). The participants were divided into two groups based on self-reported number of teeth $(<20$ teeth and $\geq 20$ teeth). Note: People generally have 28 permanent teeth; some people have 29 to 32 permanent teeth (i.e., up to four wisdom teeth may be present)." Smoking status was classified into two categories: current smoker or non-smoker. Alcohol consumption was assessed using a brief self-administered diet history questionnaire [26], which inquired about the frequency of consumption of 58 food and beverage items. The total estimated intake of food and beverage items, energy, and selected nutrients was calculated using an ad hoc computer algorithm for the questionnaire, based on the Standard Tables of Food Composition in Japan. The validity of this questionnaire has already been assessed, and it has been widely used in epidemiological nutrition studies in Japan [26-28]. Perceived mental stress was assessed via a single question: "Have you experienced dissatisfaction, distress, a hard time, or stress associated with life during the last month?" For educational status assessment, the participants were divided into three groups based on their age during their highest educational qualification: the high educational status group ( $>19$ years of age), the middle educational status group ( $\leq 18$ years of age, $>15$ years of age), and the low educational status group ( $\leq 15$ years of age). This categorization was based on the fact that people generally graduate from junior high school at 15 years of age and from high school at 18 years of age in Japan. The low educational status group and the middle educational status group consisted of people who had graduated from junior high school and senior high school respectively, while the high educational status group consisted of those who had achieved any college or higher education.

Laboratory parameters were obtained at the annual health check site during baseline. Hypertension was defined by a systolic/diastolic blood pressure $\geq 140 / 90 \mathrm{mmHg}$ (Japanese Society of Hypertension) [29], and/or treatment with antihypertensive medications [30]. The presence of diabetes mellitus (DM) was defined as fasting plasma glucose level $\geq 126 \mathrm{mg} / \mathrm{dL}$, hemoglobin A1c level $\geq 6.5 \%$ (Japanese Diabetes Society), or treatment with antidiabetic medications.

Details about the participants' death and cause of death were collected from the Summary Report of Annual Vital Statistics of Japan from the Ministry of Health, Labour and Welfare for the town of Takahata, and from the cancer registration data of the Yamagata prefecture.

\section{Statistical analyses}

The distribution of characteristics was analyzed using Mann-Whitney U-test and the chi-squared test for quantitative and qualitative variables, respectively. Hazard ratios (HR) and 95\% confidence intervals (CI) were calculated using Cox proportional-hazards regression model to assess risk factors for all-cause, cancer-, and cardiovascular disease-related mortality. In the multivariate-adjusted model, HR was adjusted for age, sex, smoking habit, alcohol consumption, educational status, hypertension, DM, and perceived mental stress. These adjusted factors for the Cox regression model have also been used in previous studies that surveyed the association between number of teeth and mortality $[13-15,19$, 21].

To examine the independent association between allcause mortality in the groups with either $<20$ or $\geq 20$ teeth and several continuous or categorical parameters, HRs and 95\% CI for the risk of all-cause mortality were calculated using Cox proportional-hazards regression analysis. A forced-entry method for the Cox proportional-hazards model with was used.

To examine whether the association between number of teeth and mortality differed according to background characteristics, subgroup analyses were performed using Cox proportional-hazards regression model, and the adjusted HR was calculated in each subgroup. Age, sex, body mass index (BMI), smoking habit, alcohol consumption, educational status, hypertension, DM, and perceived mental stress were also adjusted for in the subgroup analyses. 
Survival curves were drawn to examine the relationships between number of teeth and all-cause, cancer-, and cardiovascular disease-related mortality. These were based on Cox regression models adjusted for age, sex, BMI, smoking habit, alcohol consumption, educational status, hypertension, DM, and perceived mental stress. Statistical significance was set at $p<0.05$. Statistical analyses were performed with SPSS version 20.0 (IBM Corp., Armonk, NY, USA).

\section{Results}

The total follow-up period for the participants was $131.4 \pm 24.1$ months (mean \pm SD). For the participants who died, the follow-up period was $82.8 \pm 24.1$ months, and for the ones who survived until the end of our study, the period was $137.4 \pm 12.3$ months. During follow-up, a total of 219 deaths were recorded. Of these, the deaths that were cancer- and cardiovascular disease-related were 82 and 55, respectively. From a total of 2208 participants, 1989 participants (90.1\%) were censored; 42 of 1989 participants were lost to follow-up after moving to another area. The distribution of the clinical parameters in each group ( $<20$ and $\geq 20$ natural teeth) are shown in Table 1 . Participants with $<20$ teeth were significantly older than those with $\geq 20$ teeth. Alcohol consumption was significantly less in the participants with $<20$ teeth than in those with $\geq 20$ teeth. BMI was not significantly different between the two groups. The chi-squared test also revealed significant differences in the distribution of parameters between the two groups, which included sex, hypertension, DM, and stressful life events during the last month. There were no significant differences in the distribution of educational status and smoking habits between the two groups.

Table 2 shows unadjusted and adjusted HRs. In the unadjusted model, the risk of all-cause, cancer-related, and cardiovascular disease-related mortality was significantly higher in the group with $<20$ teeth than in the group with $\geq 20$ teeth (all-cause mortality: $\mathrm{HR}=2.658$, 95\% CI 2.030-3.479, $p<0.001$; cancer-related mortality: $\mathrm{HR}=2.127,95 \%$ CI $1.378-3.283, p=0.001$; cardiovascular disease-related mortality: $\mathrm{HR}=2.760,95 \% \mathrm{CI}$ 1.609-4.735, $p<0.001)$. In the adjusted model, the risk for all-cause mortality was significantly higher in the group with $<20$ teeth than in the group with $\geq 20$ teeth $(\mathrm{HR}=1.604,95 \%$ CI $1.007-2.555, p=0.047)$. However, the $\mathrm{CI}$ of the HR was very close to the null value and the difference was borderline significant. The risk of cancerrelated and cardiovascular disease-related mortality was not significantly higher in the group with $<20$ teeth than in the group with $\geq 20$ teeth in the adjusted model.

Table 3 shows adjusted HRs for all variables associated with all-cause mortality. Having $<20$ teeth, age, sex (male), smoking habit, and fewer episodes of perceived mental stress were independent significant risk factors for all-cause mortality.

Table 4 shows adjusted HRs for all variables associated with all-cause mortality in participants having $<20$ teeth; age and sex (male) were significant risk factors for allcause mortality.

Table 5 shows adjusted HRs for all variables associated with all-cause mortality in participants having $\geq 20$ teeth; age and smoking habit were significant risk factors for all-cause mortality.

The results of the subgroup analyses for associations between the number of teeth and all-cause mortality are shown in Table 6. The HRs for all-cause mortality were significantly higher in the group with $<20$ teeth than in the group with $\geq 20$ teeth among subgroups such as male, age $>65$ years, no smoking habits, hypertension, and non-diabetics. In particular, non-smokers with $<20$ teeth had a 2.414-fold risk for all-cause mortality compared to non-smokers with $\geq 20$ teeth. Further, non-diabetics with $<20$ teeth had a 1.715 -fold risk for all-cause mortality compared to non-diabetics with $\geq 20$ teeth. The interaction between number of teeth and age $(p=0.053)$, and between number of teeth and smoking $(p=0.055)$, showed borderline significance. However, the interactions between number of teeth and DM, and between number of teeth and hypertension, were not significant (DM: $p=0.198$, hypertension: $p=0.1421$ ).

Figures 2, 3 and 4 show the adjusted survival curves based on Cox regression model for the all-cause, cancer-, and cardiovascular disease-related mortality between participants having $<20$ and $\geq 20$ teeth. The survival rate for all-cause mortality was evidently higher in the participants having $\geq 20$ teeth than in the participants having $<20$ teeth.

\section{Discussion}

In this study, we prospectively investigated the associations between the number of teeth and mortality in a region in Japan. We observed that people with $<20$ natural teeth have a significant risk for all-cause mortality. To the best of our knowledge, this study is one of the largest studies covering a broad age range in the Japanese population, with one of the longest follow-up periods. This makes our study note-worthy.

The mechanism underlying the association between the presence of $<20$ natural teeth and the risk for allcause mortality is unclear; however, some hypotheses have been suggested. Events such as tooth loss, lead to hypoactivity of the masticatory system and ultimately, insufficient nutrient intake, which can have a negative influence on general health $[13,31]$. Yoshihara et al. reported that participants with $<20$ teeth 
Table 1 Participant characteristics

\begin{tabular}{|c|c|c|c|c|c|c|}
\hline & & \multicolumn{4}{|c|}{ Number of teeth } & \multirow[t]{3}{*}{$p$ value $^{\dagger}$} \\
\hline & & \multicolumn{2}{|l|}{$<20$} & \multicolumn{2}{|l|}{$\geq 20$} & \\
\hline & & Average & SD & Average & SD & \\
\hline & Total & $n=793$ & & $n=1407$ & & \\
\hline \multirow[t]{2}{*}{ Age (years) } & 2200 & 68.0 & 8.3 & 58.8 & 9.5 & $<0.001^{*}$ \\
\hline & Total & $n=779$ & & $n=1392$ & & \\
\hline \multirow[t]{2}{*}{ BMI $\left(\mathrm{kg} / \mathrm{m}^{2}\right)$} & 2171 & 23.4 & 4.0 & 23.4 & 3.2 & 0.275 \\
\hline & & $n=670$ & & $n=1257$ & & \\
\hline \multirow[t]{3}{*}{ Alcohol consumption (g/day) } & 1927 & 11.3 & 23.6 & 13.3 & 26.0 & 0.004 \\
\hline & & \multicolumn{4}{|c|}{ Number of teeth } & $p$ value $^{\neq}$ \\
\hline & & \multicolumn{2}{|l|}{$<20$} & \multicolumn{2}{|l|}{$\geq 20$} & \\
\hline \multicolumn{2}{|l|}{ Variable } & $n$ & $\%$ & $n$ & $\%$ & \\
\hline \multirow[t]{3}{*}{ Sex } & Male & 374 & 47.0 & 586 & 41.9 & $0.012^{*}$ \\
\hline & Female & 421 & 53.0 & 827 & 58.5 & \\
\hline & Total & 795 & & 1413 & & \\
\hline \multirow[t]{4}{*}{ Educational status } & High & 121 & 18.7 & 220 & 18.7 & 1.000 \\
\hline & Middle & 364 & 56.3 & 664 & 56.4 & \\
\hline & Low & 161 & 24.9 & 293 & 24.9 & \\
\hline & Total & 646 & & 1177 & & \\
\hline \multirow[t]{3}{*}{ Hypertension } & No & 255 & 45.5 & 594 & 60.9 & $<0.001^{*}$ \\
\hline & Yes & 306 & 54.5 & 381 & 39.1 & \\
\hline & Total & 561 & & 975 & & \\
\hline \multirow[t]{3}{*}{ Diabetes mellitus } & No & 518 & 92.3 & 934 & 95.8 & $0.005^{*}$ \\
\hline & Yes & 43 & 7.7 & 41 & 4.2 & \\
\hline & Total & 561 & & 975 & & \\
\hline \multirow[t]{3}{*}{ Current smoker } & No & 555 & 81.9 & 1022 & 80.8 & 0.584 \\
\hline & Yes & 123 & 18.1 & 243 & 19.2 & \\
\hline & Total & 678 & & 1265 & & \\
\hline \multirow[t]{5}{*}{ Perceived mental stress } & Never & 42 & 5.3 & 62 & 4.4 & $<0.001^{*}$ \\
\hline & Not very often & 244 & 31.0 & 312 & 22.2 & \\
\hline & Sometimes & 409 & 52.0 & 817 & 58.1 & \\
\hline & Most of the time & 91 & 11.6 & 214 & 15.2 & \\
\hline & Total & 786 & & 1405 & & \\
\hline
\end{tabular}

SD, standard deviation; BMI, body mass index

${ }^{+} p$ value by Mann-Whitney U-test

₹ $p$ value by chi-squared test

had a significantly lower total protein, animal protein, sodium, vitamin $\mathrm{D}$, vitamin $\mathrm{B} 1$, vitamin $\mathrm{B} 6$, niacin, and pantothenic acid intake than participants with $\geq 20$ teeth [32]. Furthermore, subjective mastication difficulties, particularly when eating hard food, begin to appear when there are $<20$ teeth in the mouth [33, 34]. Tooth loss leads to reduced nutrient intake, which, in turn, may be associated with unhealthy conditions, such as being underweight or developing certain diseases $[25,32,35,36]$. Ultimately, these factors may be linked to increased mortality.
Moreover, several studies have revealed the associations between poor masticatory function as a result of $<20$ teeth and poor cognitive function [7], risk of incident falls [8], and requirement for nursing care [9], of which are associated with mortality. Furthermore, the association between tooth loss, poor masticatory function, and mortality has also been proven epidemiologically [37]. Therefore, the association between $<20$ teeth and risk of all-cause mortality is justified.

We would also like to discuss the underlying mechanisms that associate tooth loss with the risk of all-cause 
Table 2 Cox regression analysis: Associations between the number of teeth and all-cause mortality

\begin{tabular}{|c|c|c|c|c|c|c|c|}
\hline \multirow[t]{2}{*}{ Variable } & & \multicolumn{3}{|c|}{ Unadjusted } & \multicolumn{3}{|l|}{ Adjusted } \\
\hline & & $\mathrm{HR}$ & $95 \% \mathrm{Cl}$ & $p$ value & HR & $95 \% \mathrm{Cl}$ & $p$ value \\
\hline \multicolumn{8}{|l|}{ All-cause mortality } \\
\hline Number of teeth $\geq 20$ & $(n=90 / 1413)$ & Reference & & & Reference & & \\
\hline$<20$ & $(n=129 / 795)$ & 2.658 & $(2.030-3.479)$ & $<0.001^{*}$ & 1.604 & $(1.007-2.555)$ & $0.047^{*}$ \\
\hline \multicolumn{8}{|l|}{ Cancer-related mortality } \\
\hline Number of teeth $\geq 20$ & $(n=38 / 1413)$ & Reference & & & Reference & & \\
\hline$<20$ & $(n=44 / 795)$ & 2.127 & $(1.378-3.283)$ & $0.001^{*}$ & 1.719 & $(0.798-3.700)$ & 0.166 \\
\hline \multicolumn{8}{|c|}{ Cardiovascular disease-related mortality } \\
\hline Number of teeth $\geq 20$ & $(n=22 / 1413)$ & Reference & & & Reference & & \\
\hline$<20$ & $(n=33 / 795)$ & 2.760 & $(1.609-4.735)$ & $<0.001^{*}$ & 1.289 & & 0.570 \\
\hline
\end{tabular}

Adjusted for age, sex, body mass index, smoking habit, alcohol consumption, educational status, hypertension, diabetes mellitus, and perceived mental stress $H R$ hazard ratio, $\mathrm{Cl}$ confidence interval

* Statistically significant $(p<0.05)$

Table 3 Adjusted hazard ratios and $95 \%$ confidence intervals for variables associated with all-cause mortality

\begin{tabular}{|c|c|c|c|c|}
\hline Variable & & Adjusted HR & $(95 \% \mathrm{Cl})$ & $p$ value \\
\hline Tooth number & ( $<20$ teeth $v s \geq 20$ teeth) & 1.604 & $1.007-2.555$ & $0.047^{*}$ \\
\hline Age (years) & (per 1 year increase) & 1.091 & $1.059-1.123$ & $<0.001^{*}$ \\
\hline Sex & (female vs male) & 0.434 & $0.261-0.719$ & $0.001^{*}$ \\
\hline BMI $\left(\mathrm{kg} / \mathrm{m}^{-2}\right)$ & (per 1 kg/m² increase) & 0.955 & $0.898-1.017$ & 0.150 \\
\hline Smoking habit & (Yes vs no) & 1.916 & $1.128-3.257$ & $0.016^{*}$ \\
\hline Alcohol consumption (g/day) & (per 1 g/day increase) & 0.998 & $0.989-1.007$ & 0.640 \\
\hline \multirow[t]{2}{*}{ Educational status } & (High vs low) & 0.938 & $0.557-1.527$ & 0.798 \\
\hline & (Middle vs low) & 0.701 & $0.365-1.345$ & 0.285 \\
\hline Hypertension & (Yes vs no) & 1.199 & $0.770-1.865$ & 0.422 \\
\hline Diabetes mellitus & (Yes vs no) & 1.779 & $0.960-3.296$ & 0.067 \\
\hline \multirow[t]{3}{*}{ Perceived mental stress } & (Not very often vs never) & 0.467 & $0.224-0.972$ & $0.042^{*}$ \\
\hline & (Sometimes vs never) & 0.495 & $0.247-0.992$ & $0.047^{*}$ \\
\hline & (Most of the time vs never) & 0.648 & $0.255-1.643$ & 0.360 \\
\hline
\end{tabular}

Adjusted for age, sex, body mass index, smoking habit, alcohol consumption, educational status, hypertension, diabetes mellitus, and perceived mental stress $H R$ hazard ratio, $\mathrm{Cl}$ confidence interval

* statistically significant $(p<0.05)$

mortality, based on the causes for tooth loss. Although tooth loss is primarily caused by dental caries or periodontal disease, tooth loss due to periodontitis must affect mortality differently than that due to dental caries. Periodontal disease evokes a systemic inflammatory response and increases the risk for cardiovascular disease [10-12]. Further, chronic infection and inflammation associated with periodontal disease are also thought to affect the pathogenesis of several types of cancer [21]. Moreover, the generation of carcinogens such as nitrosamines in periodontal disease is also suggested to increase the risk for cancer [10]. In recent years, several studies have reported that bacterial colonization in periodontitis may be associated with not just oral cancer, but also gastrointestinal tract cancers, such as in the colon or pancreas [38, 39]. However, the underlying mechanisms behind these associations are yet to be scientifically proven [40], warranting further studies in this regard.

This study could not confirm significant associations between the number of teeth and cancer-related mortality, which is an extremely controversial topic. Goto et al. surveyed the associations between number of teeth and cancer-related mortality, such as lung cancer, upper gastrointestinal cancer, and orodigestive cancer; significant associations were confirmed only between number of teeth and lung cancer [21]. Anzai et al. also reported similar results, confirming significant associations only between number of teeth and orodigestive cancer; the 
Table 4 Adjusted hazard ratios and $95 \%$ confidence intervals for variables associated with all-cause mortality in the group having $<20$ teeth

\begin{tabular}{|c|c|c|c|c|}
\hline Variable & & Adjusted HR & $(95 \% \mathrm{Cl})$ & $p$ value \\
\hline Age (years) & (per 1 year increase) & 1.118 & $(1.017-1.167)$ & $<0.001^{*}$ \\
\hline Sex & (female vs male) & 0.331 & $(0.107-0.645)$ & $0.001^{*}$ \\
\hline BMI $\left(\mathrm{kg} / \mathrm{m}^{-2}\right)$ & (per $1 \mathrm{~kg} / \mathrm{m}^{2}$ increase) & 0.979 & $0.901-1.065$ & 0.627 \\
\hline Smoking habit & (Yes vs no) & 1.356 & $0.659-2.788$ & 0.408 \\
\hline Alcohol consumption (g/day) & (per $1 \mathrm{~g} /$ day increase) & 1.001 & $0.988-1.014$ & 0.897 \\
\hline \multirow[t]{2}{*}{ Educational status } & (High vs low) & 1.251 & $0.657-2.379$ & 0.496 \\
\hline & (Middle vs low) & 0.984 & $0.426-2.272$ & 0.971 \\
\hline Hypertension & (Yes vs no) & 1.482 & $0.821-2.673$ & 0.192 \\
\hline Diabetes mellitus & (Yes vs no) & 1.328 & $0.588-2.995$ & 0.495 \\
\hline \multirow[t]{3}{*}{ Perceived mental stress } & (Not very often vs never) & 0.453 & $0.179-1.146$ & 0.095 \\
\hline & (Sometimes vs never) & 0.522 & $0.215-1.268$ & 0.151 \\
\hline & (Most of the time vs never) & 1.043 & $0.325-3.351$ & 0.943 \\
\hline
\end{tabular}

Adjusted for age, sex, BMI, smoking habit, alcohol consumption, educational status, hypertension, diabetes mellitus, and perceived mental stress $H R$ hazard ratio, $\mathrm{Cl}$ confidence interval, $B M I$ body mass index

* Statistically significant $(p<0.05)$

Table 5 Adjusted hazard ratios and $95 \%$ confidence intervals for variables associated with all-cause mortality in the group having $\geq 20$ teeth

\begin{tabular}{|c|c|c|c|c|}
\hline Variable & & Adjusted HR & $(95 \% \mathrm{Cl})$ & $p$ value \\
\hline Age (years) & (per 1 year increase) & 1.065 & $1.023-1.109$ & $0.002^{*}$ \\
\hline Sex & (female vs male) & 0.630 & $0.271-1.465$ & 0.283 \\
\hline $\mathrm{BMI}\left(\mathrm{kg} / \mathrm{m}^{-2}\right)$ & (per 1 kg/m² increase) & 0.912 & $0.815-1.022$ & 0.112 \\
\hline Smoking habit & (Yes vs no) & 3.711 & $1.642-8.387$ & $0.002^{*}$ \\
\hline Alcohol consumption (g/day) & (per 1 g/day increase) & 0.995 & $0.980-1.010$ & 0.532 \\
\hline \multirow[t]{2}{*}{ Educational status } & (High vs low) & 0.752 & $0.342-1.654$ & 0.479 \\
\hline & (Middle vs low) & 0.500 & $0.170-1.471$ & 0.208 \\
\hline Hypertension & (Yes vs no) & 0.756 & $0.351-1.626$ & 0.474 \\
\hline Diabetes mellitus & (Yes vs no) & 2.555 & $0.933-6.994$ & 0.068 \\
\hline \multirow[t]{3}{*}{ Perceived mental stress } & (Not very often vs never) & 0.465 & $0.128-1.690$ & 0.245 \\
\hline & (Some of the time vs never) & 0.398 & $0.117-1.355$ & 0.140 \\
\hline & (Most of the time vs never) & 0.355 & $0.070-1.812$ & 0.213 \\
\hline
\end{tabular}

Adjusted for age, sex, BMI, smoking habit, alcohol consumption, educational status, hypertension, diabetes mellitus, and perceived mental stress $H R$ hazard ratio, $C l$ confidence interval, $B M I$ body mass index

* Statistically significant $(p<0.05)$

associations with other types of cancer (lung, stomach, pancreas, colon, and liver) were not significant [18]. The mechanism underlying the association between number of teeth and cancer-related mortality is unclear. However, as previously discussed, chronic infection, inflammation, generation of carcinogens, and bacterial colonization accompanying periodontitis have been advocated as risk factors for carcinogenesis. Considering the mechanisms reported in the previous study $[18,21]$, the oral health status, including the periodontal and oral hygiene status, should play a more significant role in cancer-related mortality than the number of teeth. Future studies should attempt to assess not just the number of teeth, but also the oral health status. Furthermore, it may also be necessary to survey site-specific cancer-related mortality.

Interestingly, having $<20$ teeth was more strongly associated with all-cause mortality among the non-diabetics and non-smokers. In general, DM has various complications such as renal disease and macroangiopathy, which are known to increase mortality risk. The higher prevalence of other mortality risk factors in the diabetic participants may explain why the predictive power of tooth 
Table 6 Subgroup analysis: Associations between the number of teeth and all-cause mortality

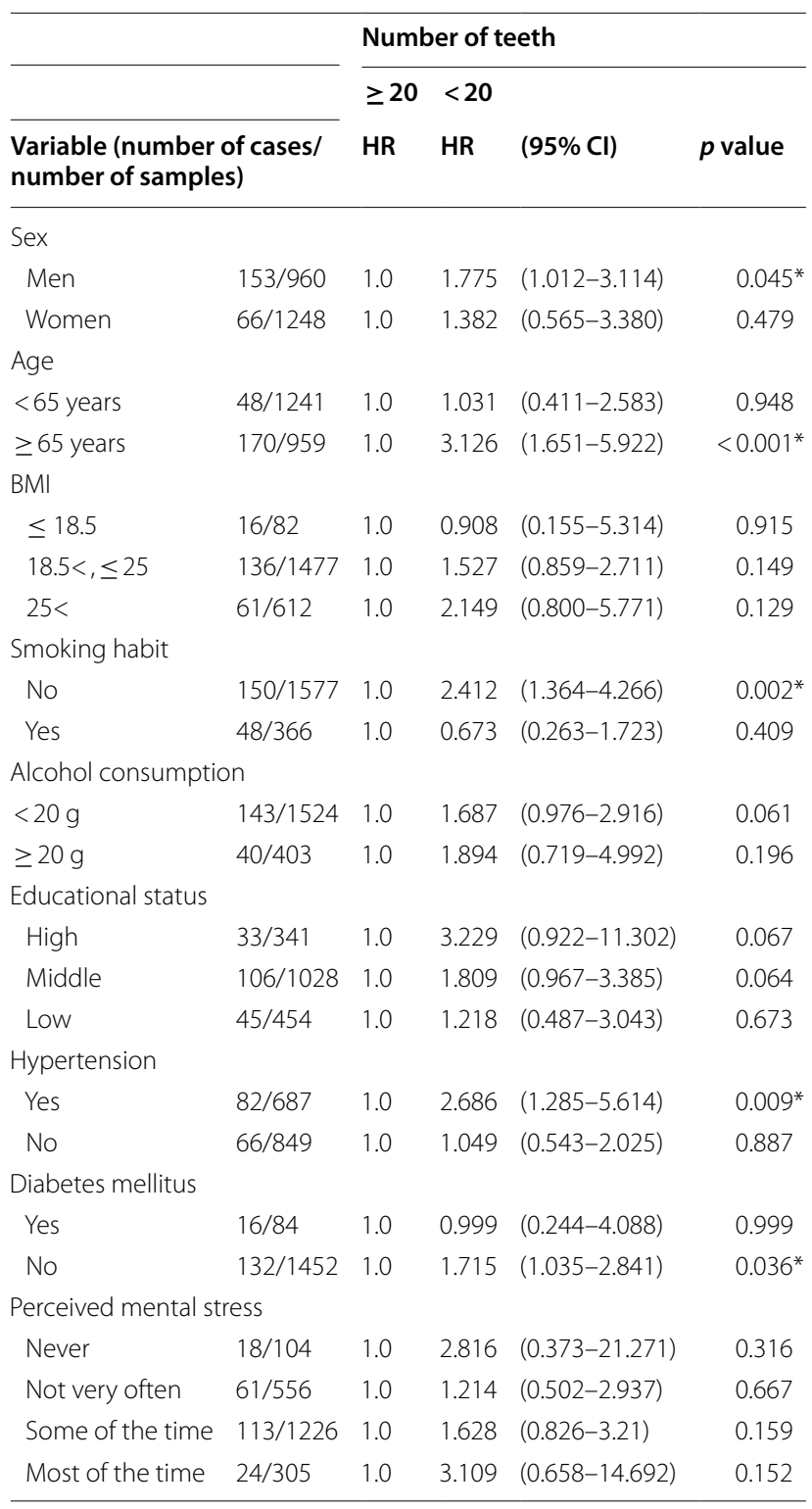

Adjusted for age, sex, BMl, smoking habit, alcohol consumption, educational status, hypertension, diabetes mellitus, and perceived mental stress

$H R$ hazard ratio, $C l$ confidence interval, $B M I$ body mass index

* statistically significant $(p<0.05)$

loss for mortality was diminished in these participants. On the contrary, the predictive power of tooth loss for mortality may be enhanced in the non-diabetics as they have a lower prevalence of other mortality risk factors than the diabetic participants. Similarly, in the nonsmoking participants, the predictive power of tooth loss for mortality was enhanced due to the lower prevalence of other mortality risk factors in the non-smokers than in the smokers. As such, there is a possibility that if an individual is relatively healthy, such as a non-smoker or a non-diabetic, the number of teeth in the individual may have a significant impact on his/her survival. However, a subgroup analysis interpretation should be performed with caution [41, 42]. Occasionally, a low statistical power may be problematic due to the reduced number of participants in the subgroup analysis. Furthermore, there was a possibility of cognitive bias in this study; i.e., the number of non-diabetics may have been under-reported. Moreover, there may be unknown confounding factors, such as economic status. Further studies are required to confirm the effects of number of teeth on relatively healthy people.

Nevertheless, the present study had several limitations. First, we surveyed the number of teeth using a selfreported questionnaire; we did not confirm the number of teeth by clinical examination. Furthermore, we did not attempt to validate the correlation between the selfreported number of teeth and that determined by clinical examination. However, several reports have revealed that the number of teeth determined by self-reports and that determined by clinical examinations showed strong correlations $[43,44]$. Thus, our methodology for confirming the number of teeth may not have influenced our results to a large extent. However, since a discrepancy between the self-reported number of teeth and that determined by clinical examination may exist, a validation for the correlation between the two counts should have been performed.

Second, we did not obtain detailed information on eating ability. A Japanese prospective cohort study surveyed the associations between oral health and cancer-, cardiovascular disease- and respiratory disease-related mortality [20]. That study showed significantly higher HRs for participants with $\leq 19$ teeth and eating difficulty in comparison to those with $\geq 20$ teeth. However, there were no significant HRs for participants with $\leq 19$ teeth and those who could eat everything in comparison to those with $\geq 20$ teeth. These results suggested that eating ability, rather than number of teeth, might affect respiratory disease- and cardiovascular disease-related mortality. These findings may elucidate our findings, which show a lack of significant association between $<20$ teeth and cardiovascular disease-related mortality. Furthermore, another recent study suggested that the number of functional teeth was a stronger predictor for all-cause mortality than the total number of teeth among community-dwelling older adults [37]. We should have surveyed not just the number of teeth, but also obtained details on eating ability. Furthermore, we did not investigate oral hygiene and periodontal status either. As previously discussed, oral health status has a greater potential to affect mortality than the number of teeth, especially 


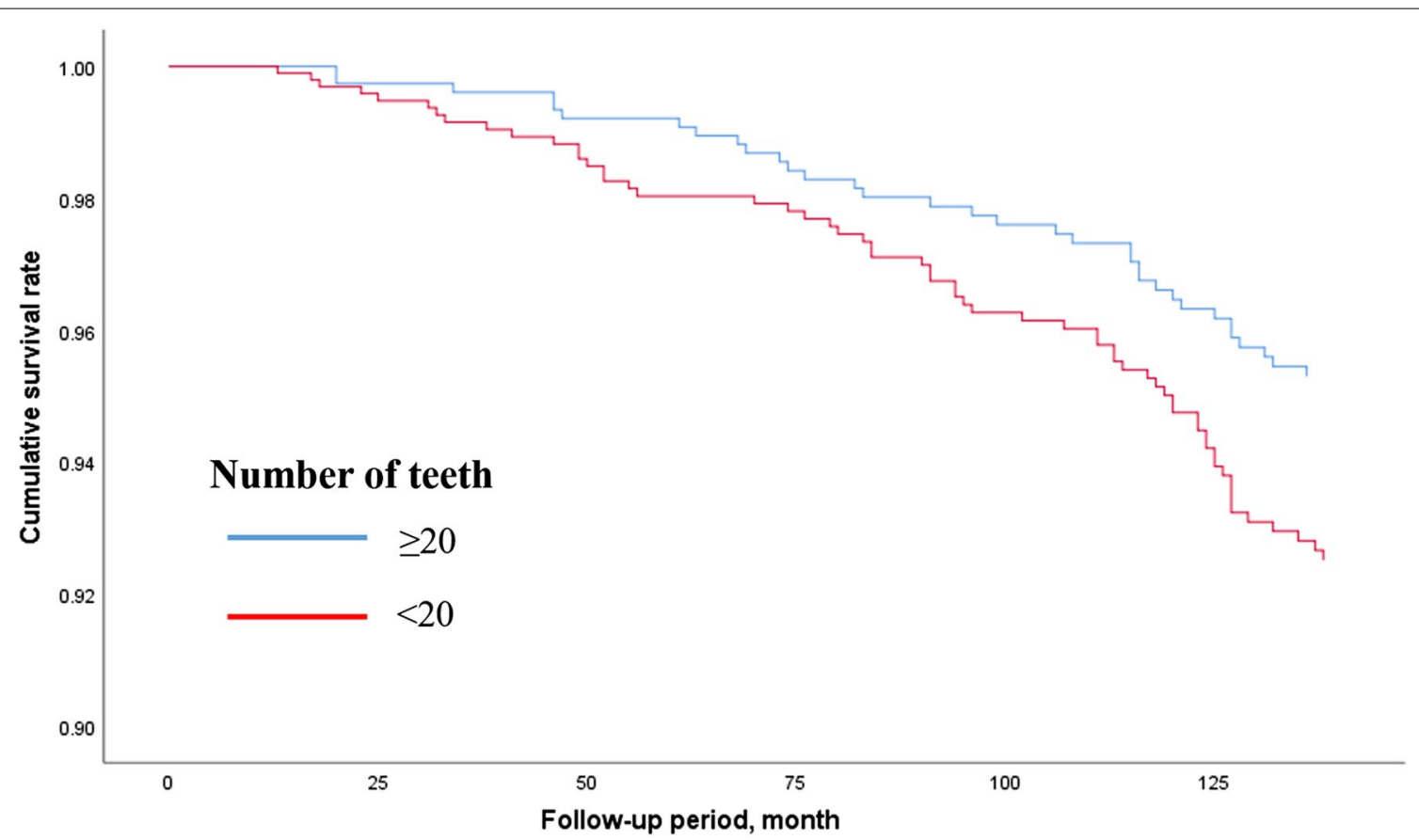

Fig. 2 Survival curve for all-cause mortality according to number of teeth based on Cox regression models adjusted by age, sex, BMl, smoking habit, alcohol consumption, educational status, hypertension, diabetes mellitus, and perceived mental stress. BMI Body mass index

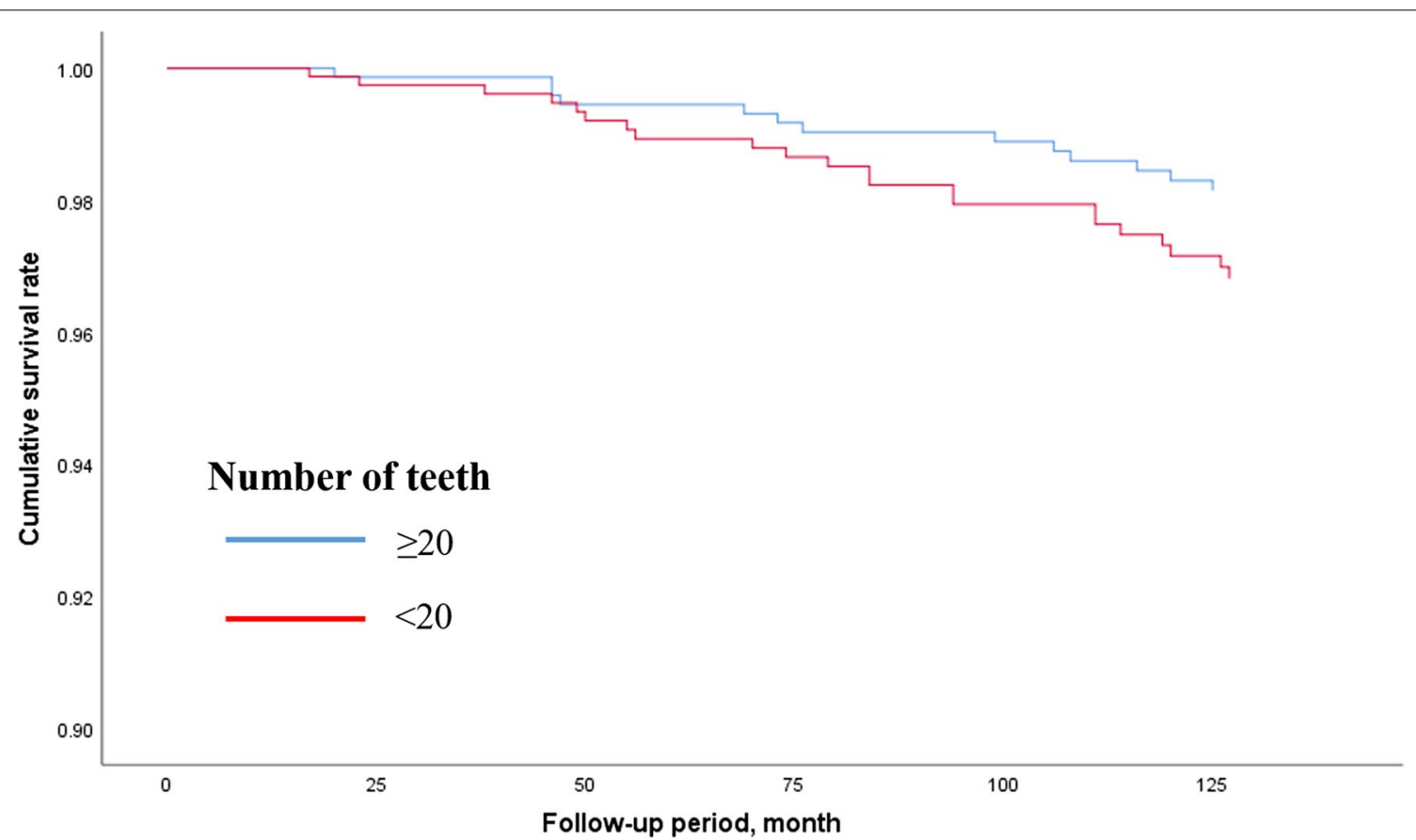

Fig. 3 Survival curve for cancer-related mortality according to number of teeth based on Cox regression models adjusted by age, sex, BMl, smoking habit, alcohol consumption, educational status, hypertension, diabetes mellitus, and perceived mental stress. BMI Body mass index 


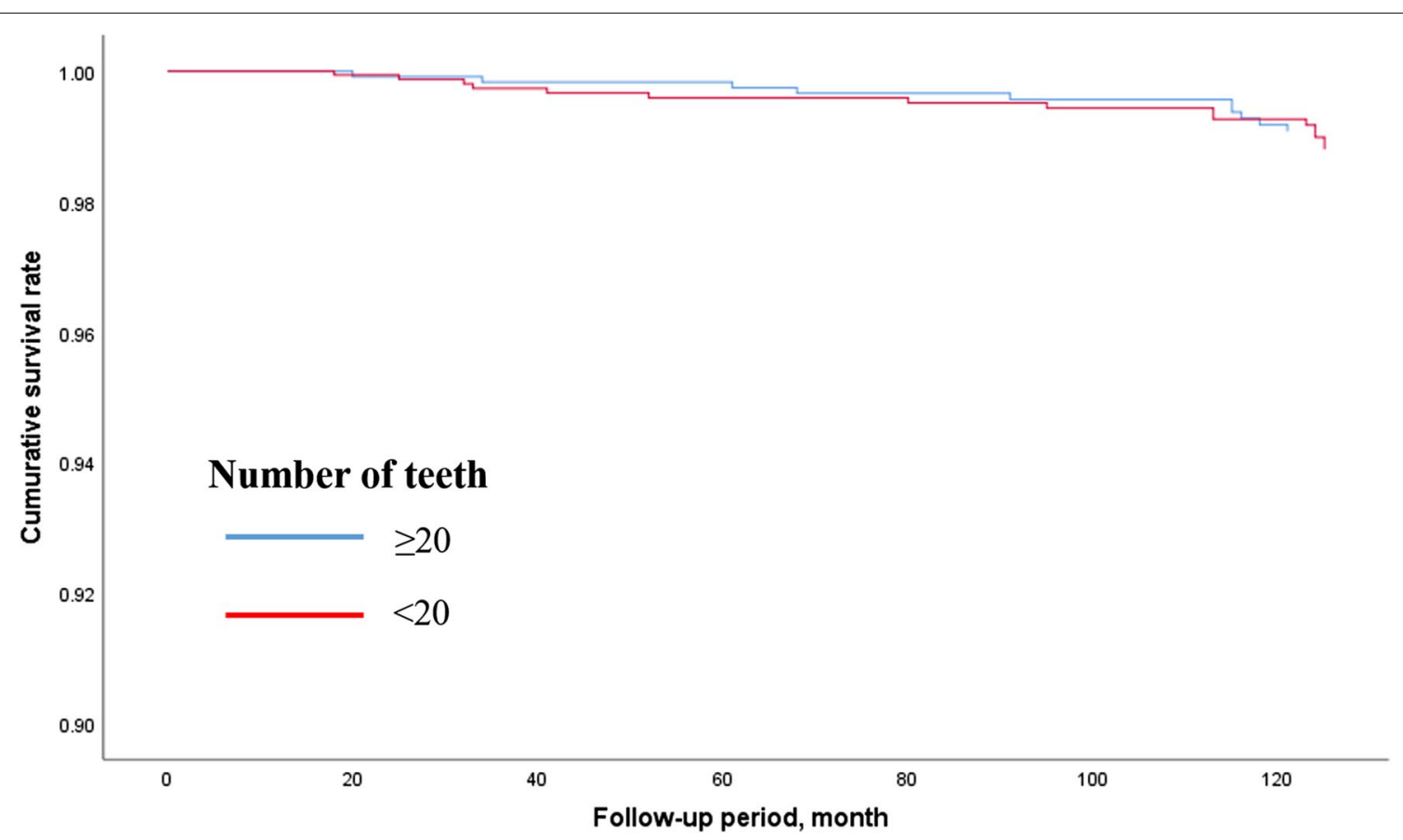

Fig. 4 Survival curve for cardiovascular disease-related mortality according to number of teeth based on Cox regression models adjusted by age, sex, BMI, smoking habit, alcohol consumption, educational status, hypertension, diabetes mellitus, and perceived mental stress. BMI Body mass index

cancer-related mortality. A comprehensive survey on the oral cavity may be required in the future.

Third, the interpretation of results in cases wherein $p$ value was close to 0.05 . In our main findings regarding the association between the number of teeth and allcause mortality, the CI of the HR for all-cause mortality was revealed to be very close to the null value (1.007), and the $p$ value also approached non-significance. Therefore, the results must be interpreted with caution. $p$ values should be considered as continuous variables rather than dichotomous ones (limited to only "significant" and "not significant") for the purpose of demonstrating how often these observations would occur by chance. If $p$ values are truly marginal, we need to take precautions to not overlook any clinically significant findings.

Fourth, was the methodology for surveying the participants' educational status. The participants were categorized into three groups (low, middle, and high educational status) based on their age during their final educational qualification. Some participants might have failed their senior high school entrance examination or repeated some of their education in senior high school; therefore, a possibility of discrepancy in the participants' true educational status cannot be denied. However, almost all the junior high school students in Japan subsequently go to high school, and most high school students graduate from high school at 18 years [24]. As such, the possibility of a discrepancy in the true educational status may not be problematic.

Fifth, the number of teeth in the participants may have changed over a period of time. There is a possibility that participants with $<20$ teeth could have restored their teeth at any time during the follow-up period, changing their status from having $<20$ teeth to $\geq 20$ teeth through the use of prostheses, such as dental implants. There is also a possibility that participants with $\geq 20$ teeth could have lost their teeth at any time during the follow-up period, changing their status from having $\geq 20$ teeth to $<20$ teeth. In this study, we only surveyed the number of teeth at baseline. Ideally, the change in the number of teeth should have been surveyed during the follow-up period as well.

Sixth, is selection bias. Our final participants may not be representative of the original target population, since 734 of 2942 participants were excluded due to incomplete data regarding their number of teeth. These excluded values may have affected the overall results.

Seventh, the participants' smoking status was coded as binary variables; i.e., current smoker or non-smoker, which encompassed past smoking history. Several studies in the literature have indicated the importance of examining lifetime smoking history, rather than just examining the smoking history at a single point in time 
[45-48]. Smoking status should have been considered a continuous variable in the statistical analysis.

\section{Conclusions}

Our study revealed that people with $<20$ natural teeth have a significant risk of all-cause mortality, although the difference was borderline significant. However, the risk of cancer- and cardiovascular disease-related mortality did not reach statistical significance between the two groups. Our findings not only emphasize the importance of having $\geq 20$ natural teeth for a healthy life expectancy, but also highlight the scope for further research in this field, with regards to data collection related to masticatory capacity, oral health status related to dental caries and periodontal disease, as well as a more detailed cause of mortality, especially cancerrelated mortality.

\section{Acknowledgements}

We thank Editage Group (https://www.editage.jp/) for editing a draft of this manuscript.

\section{Authors' contributions}

The main cohort design was drafted by TKa, HY, YU, HT, KI, TKo, and SS, and they also collected all the data. SI, TKo, and MI designed the study. SI wrote the main manuscript and prepared all tables. TKo, SS, KI, HT, YU, HY, TKa, and MI reviewed and edited the manuscript. All authors read and approved the final manuscript.

\section{Funding}

This work was supported by a grant-in-aid from the 21st Century Center of Excellence (COE) and the Global COE Program of the Japan Society for the Promotion of Science.

\section{Availability of data and material}

The raw data are confidential and cannot readily be shared. Researchers need to obtain permission from the Institutional Review Board and apply for access to the data from The Ethics Committee of Yamagata University.

\section{Ethics approval and consent to participate}

All procedures performed in studies involving human participants were in accordance with the ethical standards of the institutional and/or national research committee and with the 1964 Helsinki declaration and its later amendments or comparable ethical standards. The Ethics Committee of Yamagata University approved this study protocol. Written informed consent was obtained from all individual participants included in the study.

\section{Consent for publication}

Not applicable.

\section{Competing interests}

The authors declare that they have no conflict of interest.

\footnotetext{
Author details

${ }^{1}$ Department of Dentistry, Oral and Maxillofacial Plastic and Reconstructive Surgery, Faculty of Medicine, Yamagata University, 2-2-2 lida-nishi, Yamagata 990-9585, Japan. ${ }^{2}$ Department of Public Health and Hygiene, Yamagata University Graduate School of Medicine, 2-2-2 lida-nishi, Yamagata 990-9585, Japan. ${ }^{3}$ Department of Neurology, Hematology, Metabolism, Endocrinology and Diabetology, Yamagata University Faculty of Medicine, 2-2-2 lida-nishi, Yamagata 990-9585, Japan. ${ }^{4}$ Yamagata University Health Administration Centre, 1-4-12 kojirakawa-machi, Yamagata 990-8560, Japan. ${ }^{5}$ Global Center of Excellence, Yamagata University School of Medicine, 2-2-2 lida-nishi, Yamagata 990-9585, Japan.
}

Received: 29 June 2020 Accepted: 23 November 2020

Published online: 02 December 2020

\section{References}

1. Miyatake K. 8020 movement. J Jpn Dent Assoc. 1992;45:15-24.

2. Ueno M, Ohara S, Inoue M, Tsugane S, Kawaguchi Y. Association between education level and dentition status in Japanese adults: Japan public health center-based oral health study. Community Dent Oral Epidemiol. 2012;40:481-7.

3. Survey of Dental Diseases. Ministry of Health, Labour and Welfare, Tokyo (2016). https://www.mhlw.go.jp/toukei/list/62-28.html. Accessed 7 Dec 2019.

4. Aukes JN, Kayser AF, Felling AJ. The subjective experience of mastication in subjects with shortened dental arches. J Oral Rehabil. 1988;15:321-4.

5. Steele JG, Ayatollahi SM, Walls AW, Murray JJ. Clinical factors related to reported satisfaction with oral function amongst dentate older adults in England. Community Dent Oral Epidemiol. 1997;25:143-9.

6. Tatematsu M, Mori T, Kawaguchi T, et al. Masticatory performance in 80-year-old individuals. Gerodontology. 2004;21:112-9.

7. Yamamoto T, Kondo K, Hirai H, Nakade M, Aida J, Hirata Y. Association between self-reported dental health status and onset of dementia: a 4-year prospective cohort study of older Japanese adults from the Aichi Gerontological Evaluation Study (AGES) Project. Psychosom Med. 2012;74:241-8.

8. Yamamoto T, Kondo K, Misawa J, Hirai H, Nakade M, Aida J, Kondo N, Kawachi I, Hirata Y. Dental status and incident falls among older Japanese: a prospective cohort study. BMJ Open. 2012;2(4):e001262.

9. Aida J, Kondo K, Hirai H, Nakade M, Yamamoto T, Hanibuchi T, Osaka K, Sheiham A, Tsakos G, Watt RG. Association between dental status and incident disability in an older Japanese population. J Am Geriatr Soc. 2012;60:338-43.

10. Hiraki A, Matsuo K, Suzuki T, Kawase T, Tajima K. Teeth loss and risk of cancer at 14 common sites in Japanese. Cancer Epidemiol Biomark. 2008;17:1222-7.

11. Lee HJ, Choi EK, Park JB, Han KD, Oh S. Tooth loss predicts myocardial infarction, heart failure, stroke, and death. J Dent Res. 2019;98:164-70.

12. Schwahn C, Polzer I, Haring R, et al. Missing, unreplaced teeth and risk of all-cause and cardiovascular mortality. Int J Cardiol. 2013;167:1430-7.

13. Yuan JQ, Lv YB, Kraus VB, Gao X, Yin ZX, Chen HS, Luo JS, Zeng Y, Mao C, Shi XM. Number of natural teeth, denture use and mortality in Chinese elderly: a population-based prospective cohort study. BMC Oral Health. 2020;20:100.

14. Adolph M, Darnaud C, Thomas F, Pannier B, Danchin N, Batty GD, Bouchard P. Oral health in relation to all-cause mortality: the IPC cohort study. Sci Rep. 2017;7:44604.

15. Hu HY, Lee YL, Lin SY, Chou YC, Chung D, Huang N, Chou YJ, Wu CY. Association between tooth Loss, body mass index, and all-cause mortality among elderly patients in Taiwan. Medicine (Baltimore). 2015;94:e1543.

16. Holmlund A, Holm G, Lind L. Number of teeth as a predictor of cardiovascular mortality in a cohort of 7,674 subjects followed for 12 years. J Periodontol. 2010;81:870-6.

17. Ando A, Tanno K, Ohsawa M, et al. Associations of number of teeth with risks for all-cause mortality and cause-specific mortality in middle-aged and elderly men in the northern part of Japan: the Iwate-KENCO study. Community Dent Oral Epidemiol. 2014;42:358-65.

18. Ansai T, Takata Y, Yoshida A, Soh I, Awano S, Hamasaki T, Sogame A, Shimada N. Association between tooth loss and orodigestive cancer mortality in an 80-year-old community-dwelling Japanese population: a 12-year prospective study. BMC Public Health. 2013;13:814.

19. Hayasaka K, Tomata Y, Aida J, Watanabe T, Kakizaki M, Tsuji I. Tooth loss and mortality in elderly Japanese adults: effect of oral care. J Am Geriatr Soc. 2013;61:815-20.

20. Aida J, Kondo K, Yamamoto T, Hirai H, Nakade M, Osaka K, Sheiham A, Tsakos G, Watt RG. Oral health and cancer, cardiovascular, and respiratory mortality of Japanese. J Dent Res. 2011;90:1129-35.

21. Goto Y, Wada K, Uji T, Koda S, Mizuta F, Yamakawa M, Nagata C. Number of teeth and all-cause and cancer mortality in a Japanese community: the Takayama Study. J Epidemiol. 2020;30:213-8. 
22. Furuta M, Takeuchi K, Adachi M, Kinoshita T, Eshima N, Akifusa S, Kikutani T, Yamashita Y. Tooth loss, swallowing dysfunction and mortality in Japanese older adults receiving home care services. Geriatr Gerontol Int. 2018;18:873-80

23. Hirotomi T, Yoshihara A, Ogawa H, Miyazaki H. Number of teeth and 5 -year mortality in an elderly population. Community Dent Oral Epidemiol. 2015:43:226-31.

24. Ishikawa S, Konta T, Susa S, et al. Risk factors for tooth loss in communitydwelling Japanese aged 40 years and older: the Yamagata (Takahata) study. Clin Oral Investig. 2019;23:1753-60.

25. Ishikawa S, Konta T, Susa S, Ishizawa K, Togashi H, Ueno Y, Kubota I, Yamashita $\mathrm{H}$, Kayama $\mathrm{T}$, lino $\mathrm{M}$. Fewer teeth are a risk factor for being underweight in community-dwelling Japanese aged 40 years and older: the Yamagata (Takahata) study. Int J Dent Hyg. 2019;17:244-52.

26. Kobayashi S, Murakami K, Sasaki S, Okubo H, Hirota N, Notsu A, Fukui M, Date C. Comparison of relative validity of food group intakes estimated by comprehensive and brief-type self-administered diet history questionnaires against $16 \mathrm{~d}$ dietary records in Japanese adults. Public Health Nutr. 2011;14:1200-11.

27. Kobayashi S, Honda S, Murakami K, Sasaki S, Okubo H, Hirota N, Notsu A Fukui M, Date C. Both comprehensive and brief self-administered diet history questionnaires satisfactorily rank nutrient intakes in Japanese adults. J Epidemiol. 2012;22:151-9.

28. Ishikawa S, Ishikawa H, Shindo T, Yoshida T, Shimoyama Y, Satomi T, Fujii S, Hamamoto Y, lino M, Fukao A. Effects of occupational environmental controls and work management on chromosomal damage in dental technicians in Japan. Int J Hyg Environ Health. 2013;216:100-7.

29. Umemura S. Guidelines for the management of hypertension 2019 (2019). https://www.jpnsh.jp/data/jsh2019/JSH2019_hp.pdf. Accessed 22 July 2020

30. Sakurada K, Konta T, Watanabe M, Ishizawa K, Ueno Y, Yamashita H, Kayama T. Associations of frequency of laughter with risk of all-cause mortality and cardiovascular disease incidence in a general population: findings from the Yamagata study. J Epidemiol. 2020;30:188-93.

31. Joshipura KJ, Willett WC, Douglass CW. The impact of edentulousness on food and nutrient intake. J Am Dent Assoc. 1996;127:459-67.

32. Yoshihara A, Seida Y, Hanada N, Nakashima K, Miyazaki H. The relationship between bone mineral density and the number of remaining teeth in community-dwelling older adults. J Oral Rehabil. 2005;32:735-40.

33. Naka O, Anastassiadou V, Pissiotis A. Association between functional tooth units and chewing ability in older adults: a systematic review. Gerodontology. 2014:31:166-77.

34. Sheiham A, Steele J. Does the condition of the mouth and teeth affect the ability to eat certain foods, nutrient and dietary intake and nutritional status amongst older people? Public Health Nutr. 2001;4:797-803.
35. Kosaka T, Kida M. Tooth loss leads to reduced nutrient intake in middle-aged and older Japanese individuals. Environ Health Prev Med. 2019:24:15.

36. Kossioni AE. The association of poor oral health parameters with malnutrition in older adults: a review considering the potential implications for cognitive impairment. Nutrients. 2018;10:1709.

37. Maekawa K, Ikeuchi T, Shinkai S, et al. Number of functional teeth more strongly predicts all-cause mortality than number of present teeth in Japanese older adults. Geriatr Gerontol Int. 2020;20:607-14

38. Hujoel PP, Drangsholt M, Spiekerman C, Weiss NS. An exploration of the periodontitis-cancer association. Ann Epidemiol. 2003;13:312-6.

39. Flemer B, Warren RD, Barrett MP, Cisek K, Das A, Jeffery IB, Hurley E, O'Riordain M, Shanahan F, O'Toole PW. The oral microbiota in colorectal cancer is distinctive and predictive. Gut. 2018;67:1454-63.

40. Koka S, Gupta A. Association between missing tooth count and mortality: a systematic review. J Prosthodont Res. 2018;62:134-51.

41. Wang R, Lagakos SW, Ware JH, Hunter DJ, Drazen JM. Statistics in medicine-reporting of subgroup analyses in clinical trials. N Engl J Med. 2007;357:2189-94.

42. Sun X, Briel M, Busse JW, et al. Credibility of claims of subgroup effects in randomised controlled trials: systematic review. BMJ. 2012;344:e1553.

43. Buhlin K, Gustafsson A, Andersson K, Hakansson J, Klinge B. Validity and limitations of self-reported periodontal health. Community Dent Oral Epidemiol. 2002;30:431-7.

44. Ueno M, Shimazu T, Sawada N, Tsugane S, Kawaguchi Y. Validity of selfreported tooth counts and masticatory status study of a Japanese adult population. J Oral Rehabil. 2018:45:393-8.

45. Inoue-Choi M, Liao LM, Reyes-Guzman C, Hartge P, Caporaso N, Freedman ND. Association of long-term, low-intensity smoking with all-cause and cause-specific mortality in the national institutes of health-AARP diet and health study. JAMA Intern Med. 2017;177:87-95.

46. Holford TR, Levy DT, McKay LA, Clarke L, Racine B, Meza R, Land S, Jeon J, Feuer EJ. Patterns of birth cohort-specific smoking histories, 1965-2009. Am J Prev Med. 2014;46:e31-37.

47. Zhu SH, Sun J, Hawkins S, Pierce J, Cummins S. A population study of lowrate smokers: quitting history and instability over time. Health Psychol. 2003;22:245-52.

48. Schane RE, Ling PM, Glantz SA. Health effects of light and intermittent smoking: a review. Circulation. 2010;121:1518-22.

\section{Publisher's Note}

Springer Nature remains neutral with regard to jurisdictional claims in published maps and institutional affiliations.
Ready to submit your research? Choose BMC and benefit from:

- fast, convenient online submission

- thorough peer review by experienced researchers in your field

- rapid publication on acceptance

- support for research data, including large and complex data types

- gold Open Access which fosters wider collaboration and increased citations

- maximum visibility for your research: over 100M website views per year

At BMC, research is always in progress.

Learn more biomedcentral.com/submissions 